\title{
Carbonate in soil: A theoretical consideration on, and proposal for its fabric analysis. 2. Crystal tubes, intercalary crystals, $\mathrm{K}$ fabric
}

L. Bal

Soils Department of the State University Utrecht, Section Micropedology, Sorbonnelaan 4, Utrecht, the Netherlands

Accepted: 1 October 1974

\section{Summary}

The spatial arrangement (fabric) of carbonate in 7 different soils was studied to make a proposal for its fabric analysis. These soils, which have been developed in calcareous loess and marine deposits, are located in Afghanistan, the USSR, Germany and the Netherlands.

In the first instalment of this study (Bal, 1975) the simple plasmic fabrics crystic, calcic and fibrous have been defined. Their distinction is primarily based on theoretical considerations of Brewer's concepts (Brewer, 1964).

In this second instalment of this study the morphology and genesis of carbonate crystal tubes and intercalary carbonate crystals is dealt with.

Also K-fabric, the carbonate fabric introduced by Gile et al. (1965) is discussed and redefined. The fabrics crystic, calcic and fibrous are simple fabrics; the $\mathrm{K}$-fabric, on the contrary, is principally a compound fabric. This means that $\mathrm{K}$-fabric is composed of one or more of these simple fabrics.

\section{Introduction}

For the aim of this study, as well as for a brief characterization of the soils studied, one is referred to Part 1 (Bal, 1975). In that part a philosophy was given on the occurrence of carbonate in the soil to allow its efficient micromorphological description; this resulted in the proposed plasmic fabrics crystic, calcic and fibrous. These fabrics are essentially (more or less close) arrangements of like crystals in relation to each other.

In this second instalment of this study it will be discussed how to consider like carbonate crystals, which are not closely assembled throughout the soil material. Such crystals are distinguished as a type of pedological feature by the name of intercalary carbonate crystals. ${ }^{1}$ Moreover, attention will be paid to their genesis.

Although carbonate fabrics in the soil can be described as crystic, calcic or fibrous, in the literature also the denomination $K$-fabric (Gile et al., 1965) is used. 
In connection with the aim of the present study it is necessary to discuss the concept of $\mathrm{K}$-fabric and to compare this with the carbonate fabrics crystic, calcic and fibrous.

For a better understanding of the occurrence and formation of intercalary calcite crystals and K-fabric, this paper begins with a section on the morphology and genesis of the carbonate pedological feature named carbonate crystal tube.

\section{Discussion}

\section{Carbonate crystal tubes with coarse crystic plasmic fabric; their formation}

Crystal tubes are crystallaria' that occur in channels of simple or branching acicular shape (Brewer, 1964, p. 287).

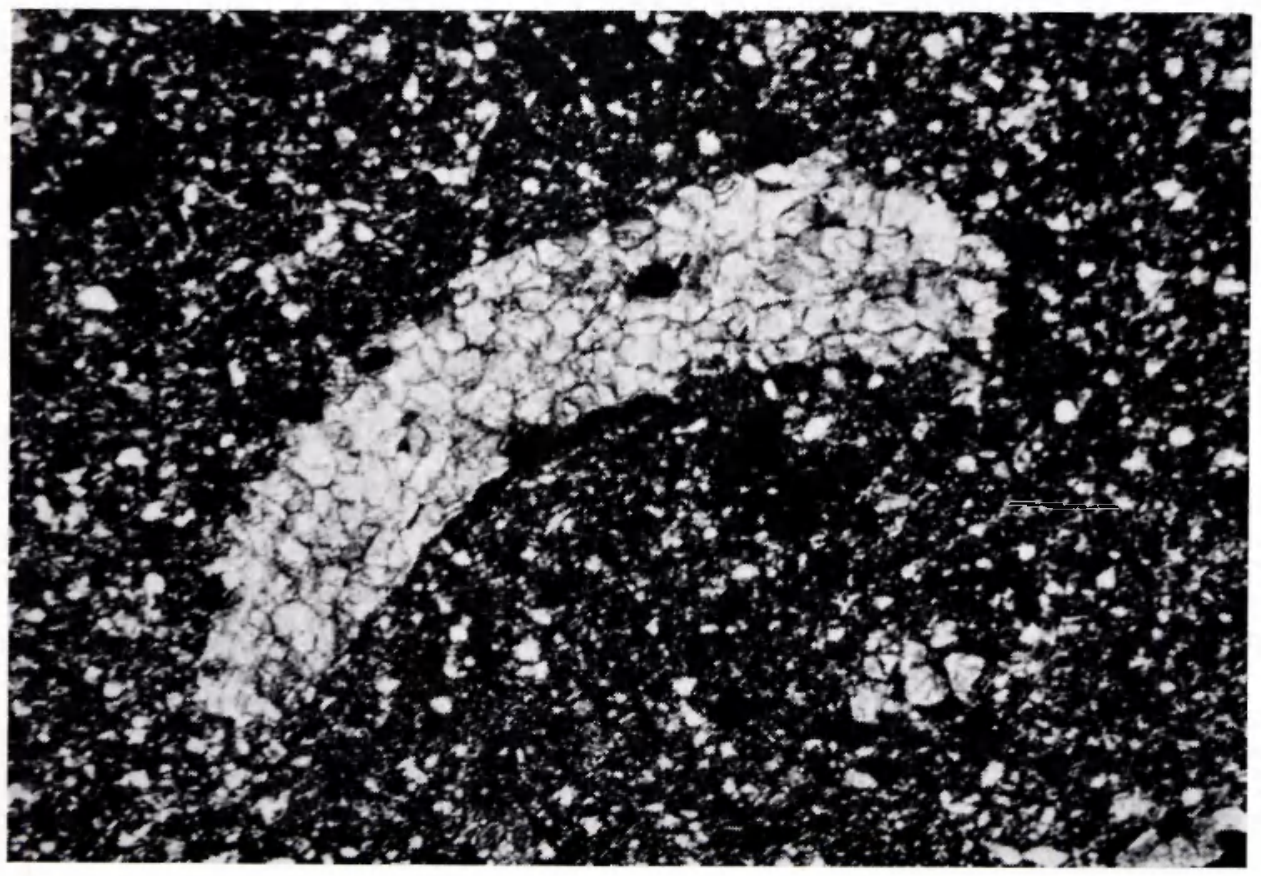

Fig. 1. Curved, carbonate crystal tube with coarse crystic plasmic fabric. Thin section from the $C$ horizon of the Pachic Vermustoll (Chernozem). Crossed polarizers. $\times 55$.

1 For the definition of pedological features one is referred to Part 1 (Bal, 1975). Brewer distinguished several groups of pedological features. One of these, the crystallaria, he defined as follows: 'Crystallaria are single crystals, or arrangements of crystals of relatively pure fractions of the plasma that do not enclose the s-matrix of the soil material but form cohesive masses; their morphology (especially shape and internal fabric) is consistent with their formation and present occurrence in original voids in the enclosing soil material.' (Brewer, 1964, p. 284). Intercalary crystals and crystal tubes both are particular types of crystallaria. 


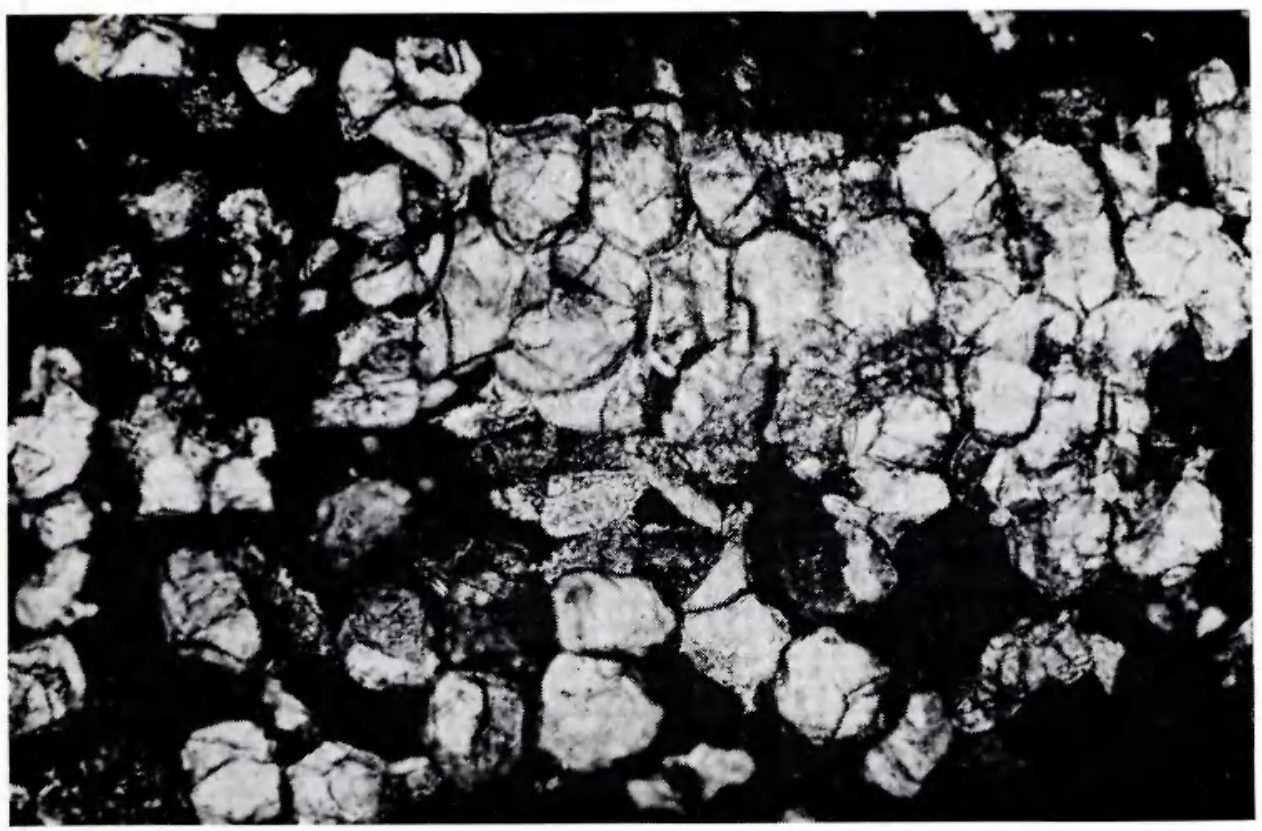

Fig. 2. Closely and regularly arranged, coarse, isodiametric, calcite crystals in a crystal tube. Some of the crystals are separated. Thin section from $30-45 \mathrm{~cm}$ in the A horizon of the Haplic Vermustoll (Tschernosem). Crossed polarizers. $\times 125$.

In carbonate crystal tubes the individual (coarse) crystals are often closely assembled (coarse crystic plasmic fabric) and may be very regularly arranged in relation to each other, sometimes creating the impression that their fabric is similar to the fabric of plant tissues. Mostly the crystals are euhedral or subhedral, and isodiametric, but they may also be elongated (Fig. 1, 2 and 3B). Until now there is no explanation for the arrangements of the crystals; one possibility will be discussed in this section.

In soils formed in calcareous loess, very coarse-grained carbonate mostly occurs in crystal tubes. The author observed such tubes especially in $\mathrm{C}$ horizons, e.g. abundantly and well-developed in the Russian Chernozem (Fig. 1); in less great numbers and much less well-developed in the Dutch Hapludalf (Fig. 3). Moreover, he observed them well-developed in the A horizon of the German Chernozem (Fig. 2). They are absent in the Afghan Xerochrept and the other soils studied.

Carbonate crystal tubes are assumed to be formations in situ which would be formed inward by crystallization from the walls of existing voids (Kubiena, 1938; Brewer, 1964, pp. 286-287). The very voids must be channels formed by plant rootlets and/or soil animals, because the tubes' diameters range in size from 100$500 \mu \mathrm{m}$ (in thin section). In $\mathrm{C}$ horizons of soils formed in loess rich in carbonate these channels are often present indeed.

It will be understandable that the formation of carbonate crystal tubes will take 


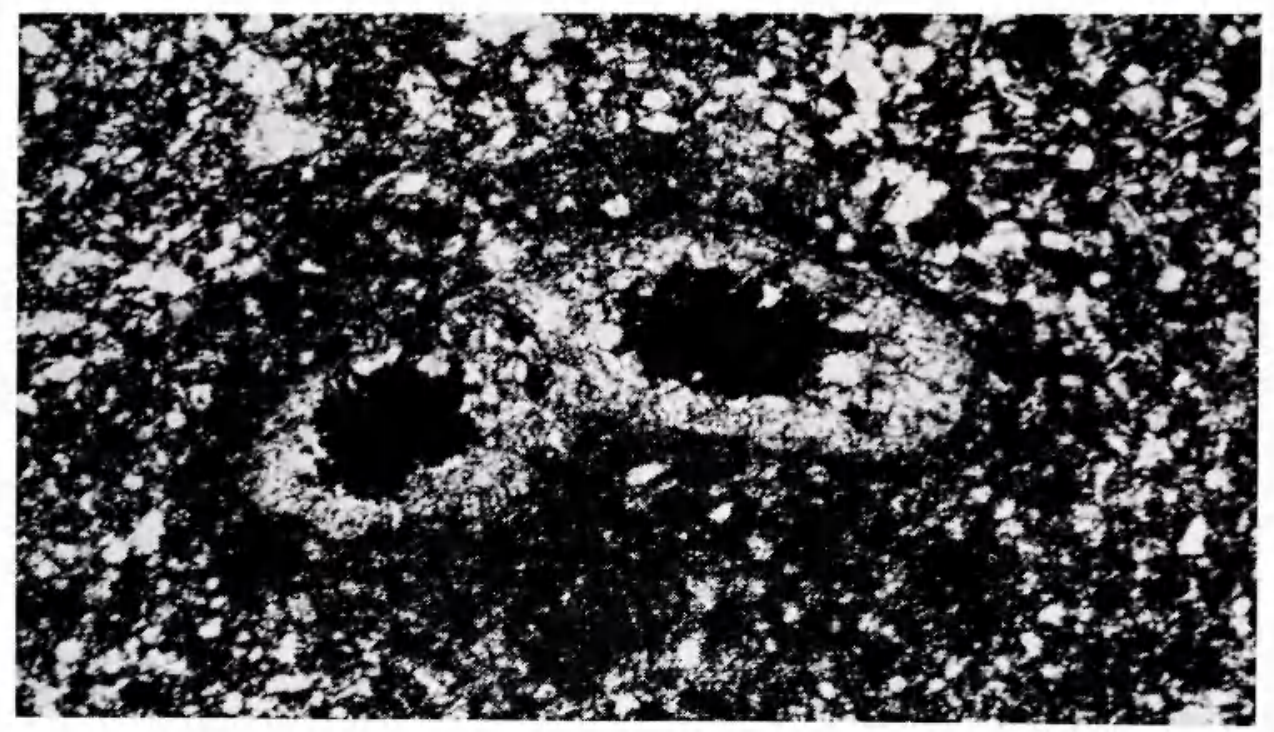

Fig. 3A. Carbonate crystal tube adjacent to a neo-calcitan (the dark zone). Unfortunately the neocutan is more or less black on the photograph, because it is gray under crossed polarizers. Thin section from the $C$ horizon of the Typic Hapludalf. Crossed polarizers. $\times 62$.

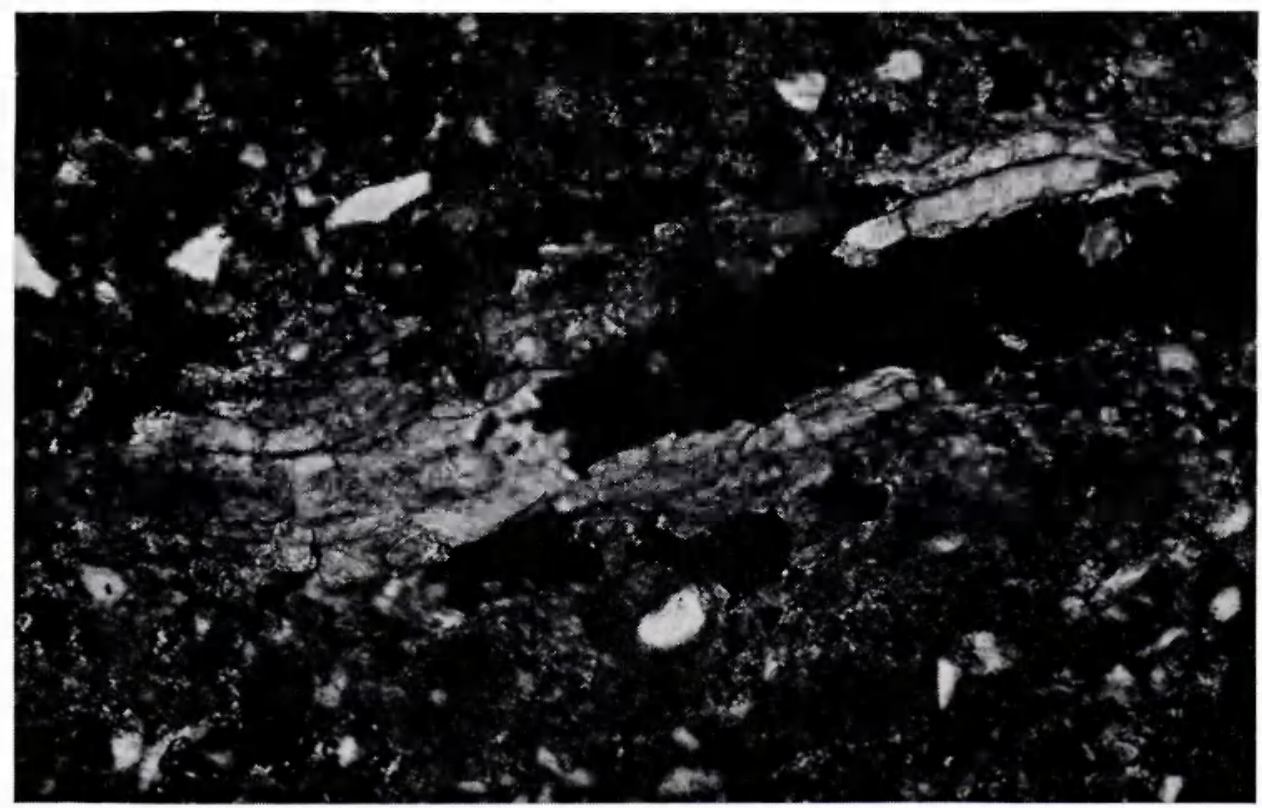

Fig. 3B. Detail of a carbonate crystal tube formed in a decaying root (carbonate root-pseudomorph). Note the large elongated crystals parallel to the tube's wall. Thin section from the $\mathrm{C}$ horizon of the Typic Hapludalf. Crossed polarizers. $\times 140$. 
time; especially as large crystals in the soil are usually assumed to form from a solution of low concentration. Thus, they will especially be present in soils (or those parts of soils), which are not subject to strong mechanical disturbance (e.g. by burrowing animals). However, biological activity must be, or have been, present to form the channels in which the carbonate crystal tubes can develop. Optimum conditions occur when the channels are more or less fossil, i.e. when soil life (inclusively rootlets) has partly or entirely disappeared. In this respect it seems justifiable to interpret many of the tubes in the Russian Chernozem as relatively old; especially those that are completely composed of closely assembled large crystals (Fig. 1). The fabric of the $\mathrm{C}$ horizon of this soil betrays that soil animals (probably earthworms) must have been active in this region of the soil.

There is some evidence that carbonate crystal tubes may also form in decaying roots; in these the individual carbonate crystals may take the shape and arrangement of the plant cells. In such cases the crystals are often elongated (Fig. 3B), but $I$ also observed crystallization in the root's periderm. This process may partly explain the different shapes and arrangements of the crystals in carbonate crystal tubes. Several carbonate crystal tubes in the $\mathrm{C}$ horizon of the Dutch Hapludalf have, at least partly, formed in decaying roots; thus, such tubes may partly be root pseudomorphs (Fig. 3B).

Formation of carbonate crystal tubes in plant roots might be initiated by nuclei present in the plantcells. For example, in the litter of the Dutch Vermudoll carbonate nodules of up to several millimetres in size are formed from small crystals of calciumoxalate, which have been formed by the plant in its cells.

Considering their different occurrence in the Russian and Dutch soil, as well as their absence in the Afghan soil one might arrive at the conclusion that the soil's $\mathrm{pH}$-curve to depth, internal drainage, and basic fabric, as well as climate may influence the tubes' formation. In this respect it is suggested that crystal tubes such as occurring in the Russian Chernozem (Fig. 1) which are composed of closely assembled large crystals; which are sharply bordered from the adjacent, quite different soil material; and which have no zone of transition in the form of a neocalcitan are characteristic of those (parts of) soils in which the $\mathrm{pH}$ is more or less steady at a high level (e.g. 7-8); under these conditions only few $\mathrm{Ca}^{2}+$ ions can be in solution. By a slow movement of soil water towards, and evaporation into the channel large crystals can form at the channel's wall.

The poorly developed crystal tubes such as in the Dutch Hapludalf (Fig. 3A) in which the large crystals adjoin neo-calcitans are thought to form in those (parts of) soils in which rather large fluctuations of the $\mathrm{pH}$ occur (e.g. 4-8). The formation of the large crystals in the tube might be different from that of the neocalcitan, i.e.:

An acid solution with $\mathrm{pH} 4-5$ from the upper part of the soil may take up rather many $\mathrm{Ca}^{2}+$ ions during its passage through the soil, particularly when it enters the calcareous part. When in the calcareous part the solution leaves the channel and, by capillary forces, enters the s-matrix with $\mathrm{pH} 7.5-8$, its $\mathrm{Ca}^{2}+$ concentration is above equilibrium. Accordingly the $\mathrm{Ca}^{2}+$ ions will precipitate more or less immediately forming fine-grained crystals (i.e. the neocalcitan). Thus, this particular neo-calcitan might be formed by illuviation instead of diffusion. 

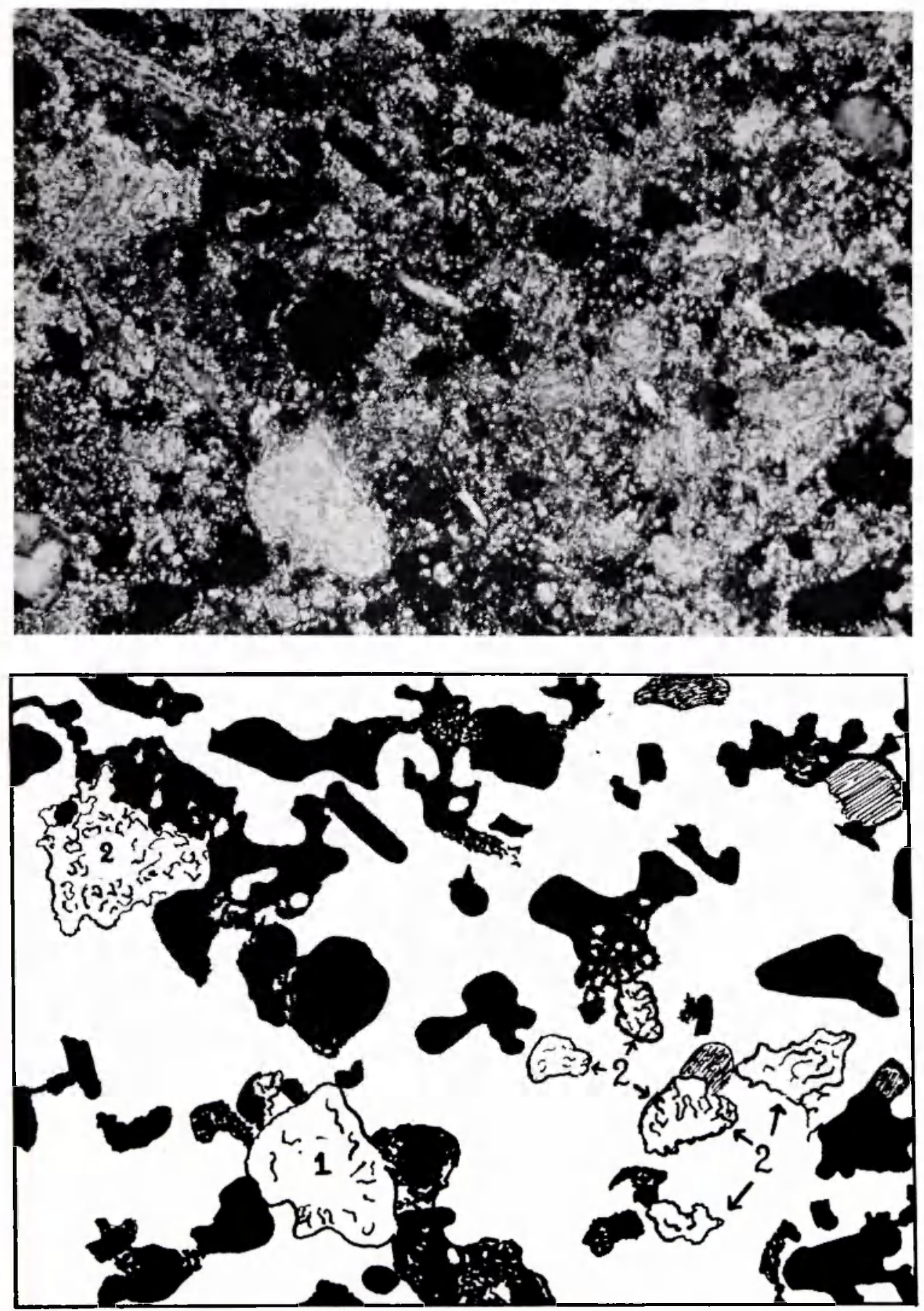

Fig. 4. In situ formation of intercalary calcite crystals from carbonate present in a fine crystic (grading into dense calcic ${ }^{10}$ ) plasmic fabric.

1. Intercalary calcite crystal (note that it is more or less elongated).

2. Several stages in their formation.

Thin section from the Calcixerollic Xerochrept (Serozem). Crossed polarizers. $\times 350$. 
The depth at which these neo-calcitans form will of course also depend on the velocity of the percolating drain water.

The large crystals in the tube, on the contrary, are formed by slow diffusion from the neocalcitan and the s-matrix.

There might be influence of the basic fabric on the tubes' formation, because this fabric may determine the drainage and evaporation of water. For example, in a soil with an agglomeroplasmic fabric the circumstances for the formation of carbonate crystal tubes are much less favourable than in a soil with a porphyroskelic fabric. Thus, apart from its intense faunal activity, the highly vughy agglomeroplasmic basic fabric, and calci ${ }^{100}$-silasepic plasmic fabric in the upper $100 \mathrm{~cm}$ of the Afghan Xerochrept (Buursink \& Bal, 1975) may also be responsible for the absence of carbonate crystal tubes in these upper $100 \mathrm{~cm}$.

With respect to climate it is especially thought of amount and spreading over a year of precipitation and evaporation.

\section{Intercalary calcite crystals; their formation}

According to Brewer (1964, p. 291) an intercalary crystal is a crystallarium consisting of a single large crystal, or a group of a few large crystals set in the soil material and apparently not associated with a void of equivalent size or shape to that of the crystallarium; the crystal(s) is (are) euhedral to subhedral having at least some well-developed crystal faces (Fig. 7).

This implies that such crystals are not considered part of a plasmic fabric, but regarded separately as individual pedological features.

When the space between well-developed crystals is large and there is no or only little carbonate finely dispersed in the soil plasma the definition of intercalary crystals is easily understandable. However, there are intergrades between carbonate occurring as intercalary crystals and carbonate occurring in calcic plasmic fabric, e.g. in the Xerochrept in Afghanistan where much fine-grained carbonate occurs between large carbonate crystals, which however are often poorly developed and/ or rounded (Fig. 6 and 7 of Part 1). As Brewer (1964) did not explain how to describe such large crystals in an arrangement similar to that of intercalary calcite crystals, but occurring in intergrades as in the Afghan Xerochrept, there should be no objection to describe these large carbonate crystals either as part of the calcic plasmic fabric (in the way proposed in Part 1) or as intercalary crystals. Usually they will be described as being part of a calcic plasmic fabric.

Intercalary carbonate crystals do not only grade into calcic plasmic fabric, but also into crystic plasmic fabric. For example, when in a group of a few large carbonate crystals the distance between the individuals becomes very small the group may be considered as a carbonate nodule with coarse crystic plasmic fabric.

Considering the basic distribution patterns described by the author earlier (Bal, 1973), the carbonate crystals occurring in crystic plasmic or calcic plasmic fabric, or as intercalary crystals may in fact also be considered being present in different basic distribution patterns. The differences between these patterns are mainly based on the size of the distance between these crystals. For example, when the crystals 


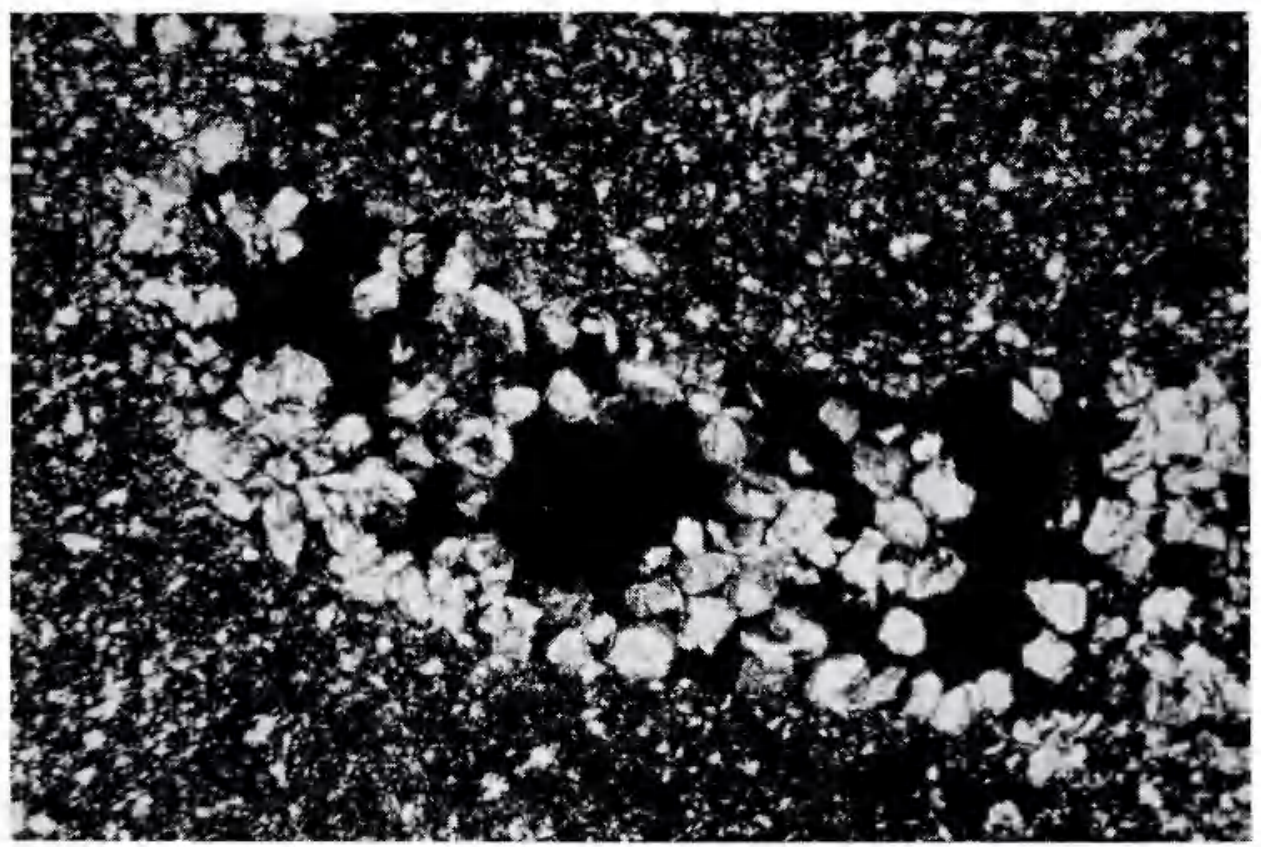

Fig. 5. Disintegrating carbonate crystal tube in the $\mathrm{C}$ horizon of the Pachic Vermustoll $($ Chernozem). Thin section under crossed polarizers. $\times 55$.

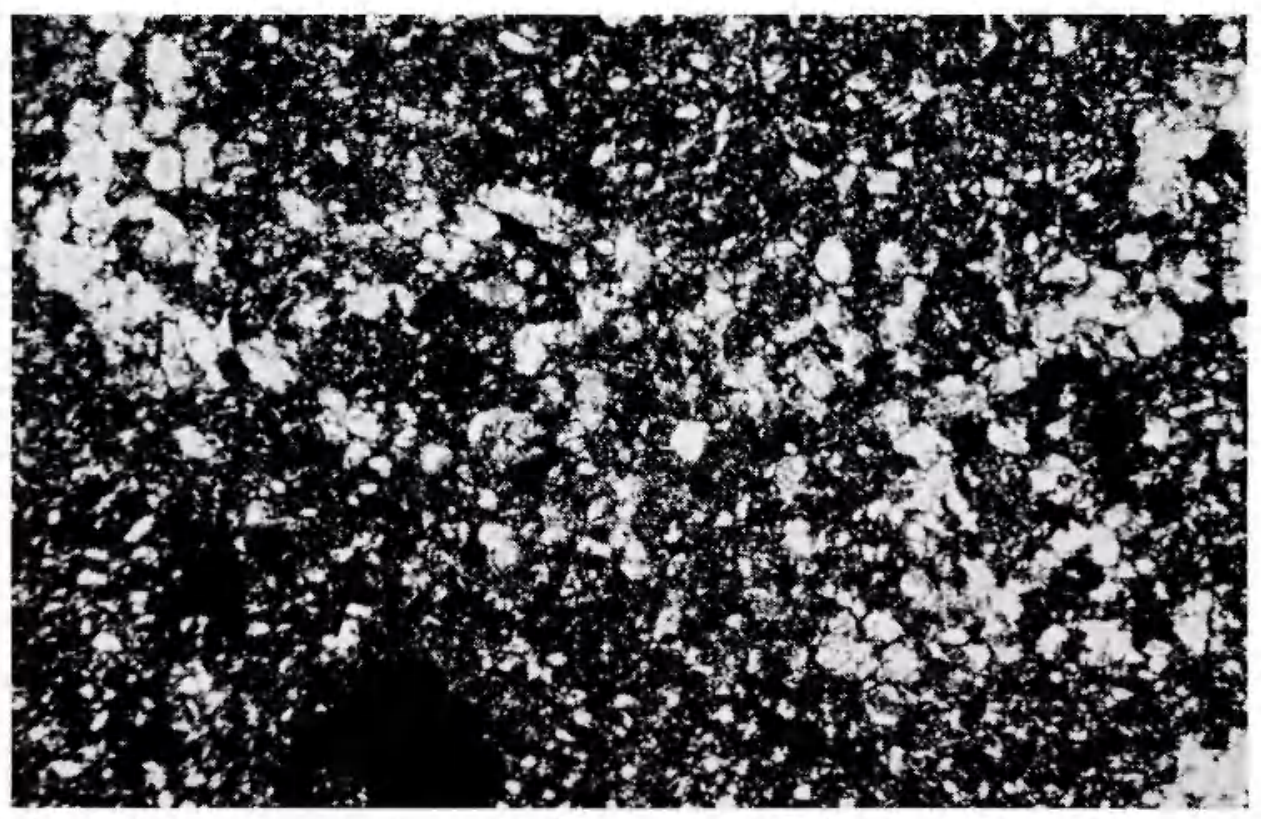

Fig. 6. Almost completely disturbed carbonate crystal tube in the $\mathrm{C}$ horizon of the Pachic Vermustoll (Chernozem). Thin section under crossed polarizers. $\times 52$. 
occur very close to each other (i.e. crystic plasmic fabric) they can be regarded as occurring in a 'welded basic distribution pattern', whereas when the crystals occur widely distributed (i.e. intercalary crystals) they can also be regarded as occurring in a 'sporadic basic distribution pattern' (Bal, 1973, p. 69).

Several possibilities for the formation of intercalary calcite crystals will be discussed here:

- Formation in situ as suggested by Brewer (1964, pp. 292-293) as follows: 'Intercalary crystals are probably due to the normal growth of larger crystals at the expense of smaller ones.' This process of formation could be clearly observed in a carbonate nodule with fine crystic (grading into dense calcic) plasmic fabric at great depth in the Xerochrept in Afghanistan. Several stages in their formation are shown in Fig. 4.

- Inheritance from the parent rock, e.g. in calcareous aeolian sediments (Wadia, 1966; Buursink \& Bal, 1975).

- Intercalary calcite crystals can also be formed by disturbance of carbonate crystal tubes of the type described in the preceding section. Disturbance of these tubes will cause the crystals to be scattered, forming intercalary calcite crystals (Fig. 6 and 7). I observed such disruption of the tubes by the soil fauna in the Russian Chernozem (Fig. 7).

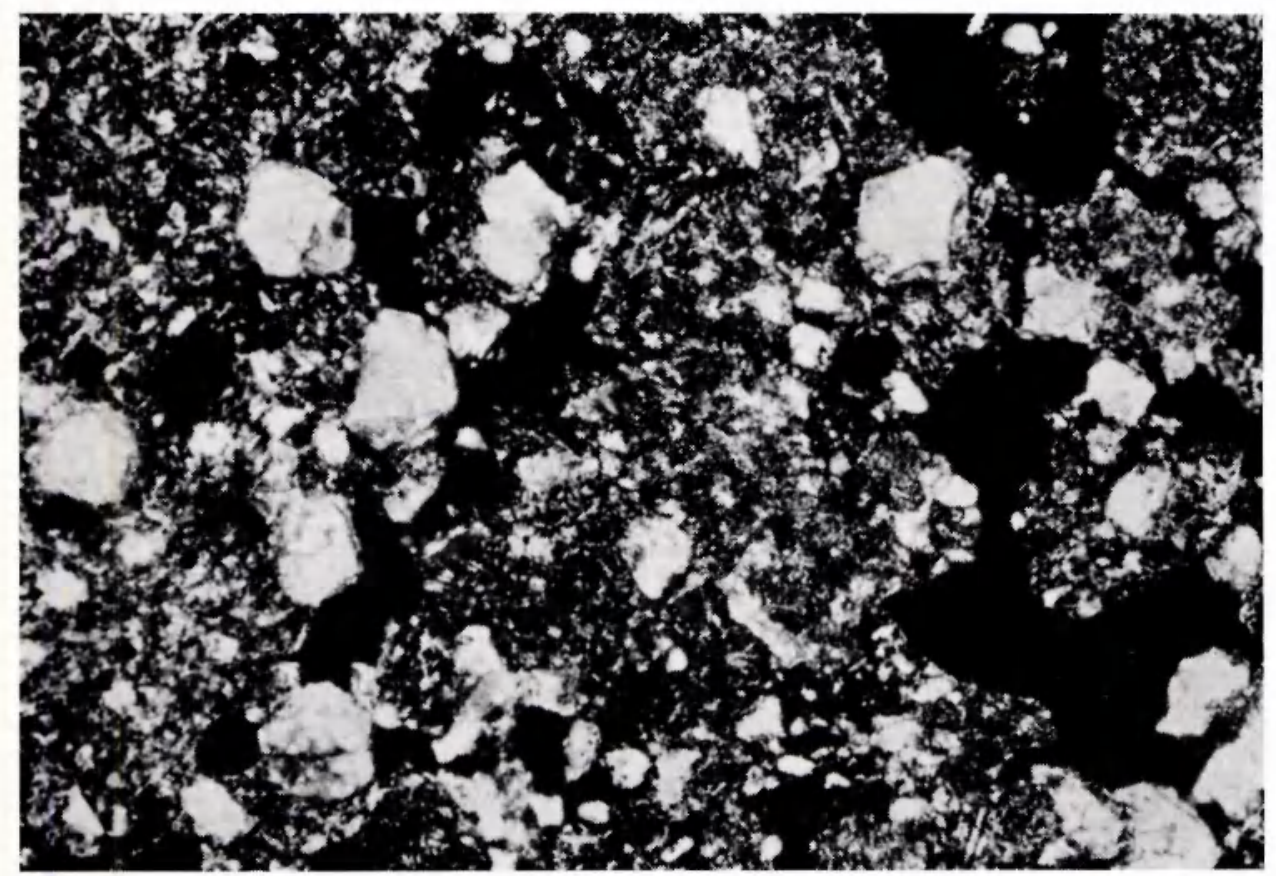

Fig. 7. Isodiametric intercalary calcite crystals formed by disturbance of a carbonate crystal tube in the $\mathrm{C}$ horizon of the Pachic Vermustoll (Chernozem). Thin section under crossed polarizers. $\times 138$. 
For one reason or another the close arrangement of the crystals in the tubes can be lost; the individual crystals are separated from each other (Fig. 5 and 2). Sometimes it may be difficult to distinguish internally disintegrated tubes from tubes in formation. In both stages: disintegration or formation, such tubes are easier to disrupt than tubes completely composed of a dense mass of crystals.

The intercalary calcite crystals formed in situ, and by inheritance in the Xerochrept in Afghanistan are often subhedral and more or less elongated (Fig. 4; and Fig. 2 and 7 of Part 1). The crystals in the Chernozem, on the contrary, are mostly euhedral to subhedral and isodiametric (Fig. 7 and 2). Their morphology (subhedral and isodiametric) must not be interpreted as being formed during transportation of the soil's parent material from elsewhere. These differences between the crystals' morphology must be explained by their process of formation. For example, subhedral crystals may be formed by a lack of available space during their crystallization, but also by physical and chemical weathering of euhedral crystals. Subhedral crystals can also be formed by partly recrystallization of small, rounded carbonate nodules with a fine crystic plasmic fabric (Buursink \& $\mathrm{Bal}$, 1975).

The morphology of the intercalary calcite crystals might give the opportunity to make an appropriate distinction between several intercalary calcite crystals based on genetic considerations.

\section{$K$ horizon and $K$ fabric}

Gile et al. (1965) introduced the concept of K horizon, which they proposed as a new master horizon to meet a need for notation and nomenclature for soil horizons of prominent carbonate accumulation. The $\mathrm{K}$ horizon has a diagnostic fabric termed $\mathrm{K}$ fabric. This proposal will be discussed here primarily because $\mathrm{K}$ fabric is also a carbonate fabric. Moreover, this particular fabric would be diagnostic for a specific type of soil horizon, i.e. it would indicate particular soil forming processes.

\section{$K$ fabric. Gile et al. (1965) defined K fabric as follows:}

'In $\mathrm{K}$ fabric, fine-grained authigenic carbonate occurs as an essentially continuous medium. It coats or engulfs, and commonly separates and cements skeletal pebbles, sand, and silt grains. Interstices between skeletal grains are partly or completely filled with carbonate. In materials with minimal carbonate contents for the expression of $\mathrm{K}$ fabric, mere juncture of thin carbonate coating in the angles at contacts between skeletal grains establishes continuity of the carbonate. Juncture of the carbonate coatings can be missing at a few contact points, or a small portion of the skeletal grain surfaces can be free of carbonate coating, without negating the essential continuity of the carbonate matrix. The boundary between the authigenic carbonate matrix and allogenic noncarbonate grains is obvious, because of the prominent mineralogical differences. The boundary between the authigenic carbonate and fragments of limestone or other allogenic carbonate is marked by changes in colour and crystal size or orientation (the latter two as viewed in thin section).'

Although $\mathrm{K}$ fabric is also a carbonate fabric, it differs from the fabrics crystic, calcic and fibrous for two reasons, which are: firstly the different meaning given to the concept of fabric by Brewer (1964) and Gile et al. (1965); and secondly in 
an organization of spatial arrangements of soil materials the fabrics crystic, calcic, and fibrous represent a low level, whereas the $\mathrm{K}$ fabric represents a higher one. Some explanation on these differences is necessary.

Fabric. According to Gile et al. (1965) a particular fabric composed of finegrained carbonate may be mentioned $\mathrm{K}$ fabric only when this carbonate is authigenic. ${ }^{2}$ This implies that an exactly similar arrangement of fine-grained allogenic carbonate ${ }^{2}$ should not be mentioned $\mathrm{K}$ fabric. Accordingly, Gile et al. give the concept of fabric a genetic bearing. However, from a soil morphological point of view it is more desirable to use the term fabric purely morphologically as it has been defined by Brewer (1964). According to Brewer (1964, p. 131) fabric deals with arrangement only and does not imply any genetic interpretation.

Brewer's concept of the term fabric is to be preferred, as morphologically it is often very difficult, or even impossible, to establish whether the carbonate is authigenic or allogenic (Parfenova et al., 1965; Siderius, 1973; Bal, 1975; Buursink \& Bal, 1975). For example, carbonate glaebules may have a fine-grained internal fabric, but their origin may not always be established with certainty (see e.g. Siderius, 1973, p. 123). Also, one might wonder whether carbonate glaebules, which have been formed in the subsoil, but moved to another horizon by churning (suggested by Blokhuis et al., 1968-1969, but questioned by Buursink, 1971, p. 234) are still authigenic.

These examples illustrate the less practical aspect in the concept of $\mathrm{K}$ fabric according to Gile et al. (1965). Whereas in calcareous soil materials the arrangement of the carbonate crystals may meet the requirements of $\mathrm{K}$ fabric, one cannot always take the decision whether these soil materials have $\mathrm{K}$ fabric, because one does not know their genesis.

Before discussing the afore-mentined difference in level of organization it is useful to discuss the $\mathrm{K}$ horizon.

$K$ horizon. Gile et al. (1965) consider K fabric to be diagnostic of the $\mathrm{K}$ horizon. As their definition of $\mathrm{K}$ fabric is restricted to fine-grained carbonate, this implies that coarse-grained and needle-shaped carbonate are excluded from the K horizon. ${ }^{3}$

However, in the present author's opinion the most important feature of the $\mathrm{K}$ horizon should be the presence of a certain quantity of authigenic carbonate as it is only by this criterion that the soil material may be designated as a horizon. The concept of $\mathrm{K}$ horizon should not exclusively be determined by the size and shape of the carbonate crystals. It is therefore wondered why Gile et al. state that

2 In situ accumulations of $\mathrm{CaCO}_{3}$ are known as 'authigenic' (Gile et al., 1965), or as 'pedogenic' (Blokhuis et al., 1968-1969; Sehgal et al., 1972), or as 'secondary' (Parfenova et al., 1965, p. 88; Sehgal et al., 1972; Kowalinski et al., 1972), or as 'autochthonous' (Hrasko et al., 1972).

Carbonate accumulations inherited from the parent rock are often distinguished as 'allogenic' (Gile et al, 1965), or as 'primary' (Parfenova et al., 1965, p. 88; Kowalinski et al., 1972; Sehgal et al., 1972), or as 'allochthonous' (Hrasko et al., 1972).

${ }^{3}$ Carbonate grains are generally more or less isodiametric crystals (e.g. Fig. 7; and Fig. 1 in Part 1), whereas needles are extremely developed in one direction (Fig. 8 and 9 in Part I). 
this authigenic carbonate should be fine-grained. Although this is presumably its most common form (Parfenova et al., 1965, p. 87) the restriction is unwarranted, because authigenic carbonate may very well be coarse-grained, or needle-shaped as it has been demonstrated in the preceding sections of the present paper and in Part 1 of this study (Bal, 1975). Moreover, it is a known phenomenon in the literature (Parfenova et al., 1965, pp. 79 and 89; Hrasko et al., 1972; Buursink \& Bal, 1975). The present author observed that authigenic carbonate in a fine crystic, coarse crystic, and in a fibrous fabric may even occur together in the same horizon of a soil even in rather large amounts (e.g. in the German Chernozem).

A difficulty in the determination of a $\mathrm{K}$ horizon is the decision whether the carbonate present is authigenic or allogenic; a decision to be taken from the carbonate's fabric. In some cases one can deduce with certainty from this fabric that the carbonate is authigenic, e.g. when it occurs in a fibrous fabric in voids (Fig. 8 - 10 of Part 1), or when it occurs in void (neo-)cutans, or crystal tubes (Fig. 1, 2, 3 and 5; Bal, 1975, Fig. 4). Sometimes one can also observe authigenic carbonate in nodules especially when the boundaries of these are diffuse. However, as mentioned before often it may morphologically be difficult or even impossible to establish whether the carbonate is authigenic or allogenic (Parfenova et al., 1965; Siderius, 1973; Buursink \& Bal, 1975).

In the author's opinion the decision whether a horizon may be distinguished as a $\mathrm{K}$ horizon could also be based on other observations. For example, from the study of the geomorphology and ground water (its flow direction and chemical analysis) one could learn that carbonate in solution moves from a calcareous rock to the soil's parent material where it precipitates.

However, apart from the way in which the horizon will be determined as $\mathrm{K}$ horizon it is necessary to specify its fabric. A fabric in which the occurrence of carbonate must be described and which can be named $\mathrm{K}$ fabric. As already was stated by Gile et al. (1965) a requirement for this fabric is that the carbonate occurs as an essentially continuous medium. The way in which this continuity presents itself does not matter, whether this is through carbonate dispersed in peds, or by carbonate cutans, or in some other way. This implies that the carbonate in the whole horizon may occur entirely in dense calcic fabric, or parts of the horizon are characterized by fine crystic fabric (e.g. in carbonate nodules), whereas other parts may be characterized by coarse crystic fabric (e.g. in crystallaria), and/or by fibrous fabric (e.g. in cutans).

From this the difference in level in organization between $\mathrm{K}$ fabric on the one hand and calcic, crystic, and fibrous fabric on the other is evident.

Difference in level in organization between $K$ fabric, and the carbonate plasmic fabrics calcic, crystic and fibrous. When in the morphological description of a soil material the plasmic fabric is characterized by a particular type, this type is meant to occur throughout the soil material, unless otherwise stated.

According to Brewer (1964, p. 10) the soil material is the unit of study; it is that unit in which the characteristics being studied are relatively constant. The soil material may be e.g. a nodule, a crystallarium, a cutan, or even a horizon. 
$\mathrm{K}$ fabric of a soil material, on the contrary, may be composed of al types of carbonate plasmic fabrics, which in their turn may be characteristic of several units of organization of lower level (usually pedological features) present in this soil material. For example, the soil material may be a ped characterized by the following type of $\mathrm{K}$ fabric: part of the carbonate occurs in calcic fabric in the ped's s-matrix, whereas another (great) part occurs in fine crystic fabric in a (partly) embedded carbonate nodule, the remainder of the carbonate occurs in fibrous fabric in a cutan covering that part of the nodule where this borders to a void (an example more or less demonstrated in Fig. 10 of Bal, 1975). Or in other words: in an organization of soil materials the plasmic fabrics calcic, crystic and fibrous represent a low level whereas $\mathrm{K}$ fabric would represent a higher level. Thus, from the aforesaid $\mathrm{K}$ fabric could be better defined as follows:

' $K$-fabric is the spatial arrangement of grained and/or needle-shaped carbonate in such a way that it occurs as an essentially continuous medium throughout the soil material including present pedological features. The carbonate may occur in a calcic and/or crystic and/or fibrous plasmic fabric.'

\section{Conclusion}

More or less closely assembled calcite crystals are considered (part of) the plasma of the soil material in which they occur (see Bal, 1975). However, in case the distance between large (usually euhedral or subhedral) crystals is considerable, these crystals are not considered being part of the plasma of the soil material in which they occur, but as separate soil materials (i.e. intercalary crystals) set in this soil material. Particularly when between the large crystals carbonate is (seemingly or almost) lacking. When, on the contrary, the space between large, but often poorly developed and/or rounded calcite crystals is occupied by fine-grained calcite, these crystals may also be regarded as part of the calcic plasmic fabric.

The calcic, crystic, and fibrous plasmic fabrics are simple fabrics (see Bal, 1975). $\mathrm{K}$ fabric, on the contrary, is a compound fabric composed of carbonate plasmic fabrics. $\mathrm{K}$ fabric is in fact an 'overall' carbonate fabric, in which the only important characteristic is that the carbonate forms a continuum throughout the soil material. The way in which this continuity presents itself is not important. The carbonate may be part of the s-matrix, but it may also occur in pedological features as cutans, nodules, etc.

$\mathrm{K}$ fabric is a morphological denomination; it is not restricted to authigenic carbonate.

Intercalary calcite crystals do not only form in situ sensu stricto as usually suggested. They can also be formed by disturbance of carbonate crystal tubes with a coarse crystic plasmic fabric. For example, the disturbance can be caused by the burrowing soil fauna. Intercalary calcite crystals can even be inherited from the parent rock.

Carbonate crystal tubes are assumed to be formations in situ occurring in soils (or those parts of soils), which are characterized by little mechanical disturbance. 
Moreover, climate, the soil's fabric and $\mathrm{pH}$-curve to depth might influence their formation; some tubes may (at least partly) be root pseudomorphs.

\section{References}

Bal, L., 1970. Morphological investigations in two moder-humus profiles and the role of the soil fauna in their genesis. Geoderma 4: 5-36.

Bal, L., 1973. Micromorphological Analysis of Soils. Soil Survey Papers No 6, Netherlands Soil Survey Institute, Wageningen, $174 \mathrm{pp}$. (Also issued as Doctoral Thesis and obtainable from the author.)

Bal, L., 1975. Carbonate in soil: A theoretical consideration on, and proposal for its fabric analysis. 1. Crystic, calcic and fibrous plasmic fabric. Neth. J. agric. Sci. 23: 18-35.

Blokhuis, W. A., Th. Pape \& S. Slager, 1968-1969. Morphology and distribution of pedogenic carbonate in some vertisols of the Sudan. Geoderma 2: 173-200.

Brewer, R., 1964. Fabric and mineral analysis of soils. Wiley, New York, $470 \mathrm{pp}$.

Buursink, J., 1971. Soils of Central Sudan. Soils Department, State University, Utrecht, the Netherlands, $249 \mathrm{pp}$.

Buursink, J. \& L. Bal, 1975. An inceptisol formed in calcareous loess on the 'Dast-i-Esan Top' plain in North Afghanistan. Fabric, mineral and trace element analysis (in press).

Gile, L. H., F. F. Peterson \& R. B. Grossman, 1965. The K horizon: A master soil horizon of carbonate accumulation. Soil Sci. 99: 74-82.

Hrasko, J., Z. Bedrna \& J. Curlik, 1972. Some forms of carbonates in the soils of Slovakia. In: S. A. Pieniazek, S. Kowalinski, J. Drozd \& S. Licznar, (Ed.), Soil micromorphology. Proc. 3rd. int. Working Meet. Soil Micromorphol. (Wroclaw, Poland, 22-28 September, 1969): 159-167. Polska Akademia Nauk, Zeszyt 123, Panstwowe Wydawnictwo Naukowe, Warszawa.

Kowalinski, S., L. J. Pons \& S. Slager, 1972. Micromorphological comparison of three soils derived from loes in different climatic regions. Geoderma 7: 141-158.

Kubiena, W. L., 1938. Micropedology. Collegiate Press, Ames, Iowa, 243 pp.

Parfenova, E. J. \& E. A. Yarilova, 1965. Mineralogical investigations in soil science. Israel Program for Scientific Translations, Jerusalem, $178 \mathrm{pp}$.

Sehgal, J. L. \& Stoops, G., 1972. Pedogenic calcite accumulation in arid and semi-arid regions of the Indo-Gangetic alluvial plain of Erstwhile Punjab (India) - Their morphology and origin. Geoderma 8: 59-72.

Siderius, W., 1973. Soil transitions in Central East Botswana (Africa). Publication of the International Soil Museum, Utrecht - International Institute for Aerial Survey and Earth Sciences (ITC), Enschede, the Netherlands, $260 \mathrm{pp}$.

Wadia, D. N., 1966. Geology of India. MacMillan, London, 536 pp. 